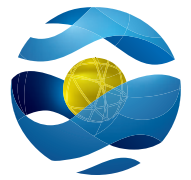

\title{
An advocacy organization to support animal research
}

The Federation of American Societies of Experimental Biology (FASEB) was founded in 1912 by delegates from the American Physiological Society, the American Society for Biochemistry and the American Society for Pharmacology and Experimental Therapeutics. Its first Executive Committee meeting in 1913 resulted in a declaration on animal experimentation that was published in Science in 1914.

The four-paragraph declaration asserts support for animal experimentation: "We emphasize the necessity of animal experimentation...in the future." It further asserts opposition "to cruelty to animals" and assurance that "the vast majority of experiments on animals need not be and, in fact, are not accompanied by any pain whatsoever." Finally, it expresses regret for "the widespread lack of information regarding the aims, achievements and procedures of animal experimentation."

Almost 100 years later, FASEB is still working to promote biomedical research, and its homepage provides a good introduction to its work. The navigation bar at the top of the page includes a tab titled 'What We Do' that explains FASEB's role in advocacy for medical research policy.

Below the navigation bar, a rotating banner on the left-hand side promotes The FASEB Journal; Science's online career planning tools; FASEB's publication, Breakthroughs in Bioscience; and FASEB's association management services for federation members, among other resources. Perhaps the most important to scientists given the current decrease in federal research dollars is FASEB's pamphlet on Federal Funding for Biomedical and Related Life Sciences Research FY2014, which includes its recommendations on federal science- and medicine-related funding to the National Institutes of Health (NIH), National Science Foundation, Department of Energy Office of Science, Department of Veterans Affairs and the US Department of Agriculture. The pamphlet can be downloaded as a 16-page PDF file. A fact sheet on Sequestration Cuts Biomedical \& Biological Research can also be downloaded.

Immediately to the right on the homepage is a 'Video Spotlight,' which displays short videos related to federal science budgets and FASEB's centennial (celebrated in 2012). They are interesting but dated.

The rest of the homepage is dedicated to the latest news from FASEB, a calendar of meetings and a teaser for a list of available jobs. The news included comments on an NIH Request for Information on developing an "NIH data catalog to document publically available datasets and house related metadata." FASEB pointed out barriers for

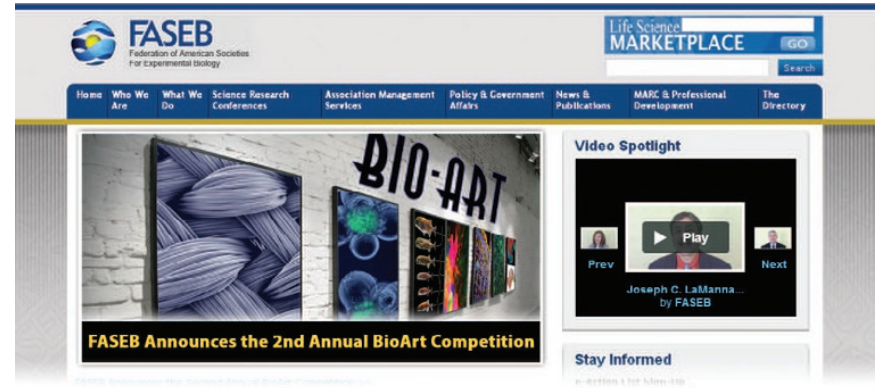

establishing such a catalog, including, most importantly, "the lack of incentive for researchers to submit catalog entries."

Returning to the navigation bar, the 'Who We Are' tab leads to lists of the 27 current FASEB member societies, the meetings sponsored by these societies, the awards they give, the 155 Nobel Prize winners who have been members of FASEB member societies and the career development and minority affairs initiatives they offer. The tab has information about FASEB, including its campus in Bethesda, MD; jobs available within the organization; and how the organization is run.

The 'What We Do' tab, as noted above, leads to information on how FASEB advocates for the more than 100,000 scientists represented by its member societies. The 'Policy \& Government Affairs' tab leads to a page that includes FASEB's NIH Factsheets for each US state, giving information on the amount of NIH grant money that flowed into the state and its institutions in FY2012 and in the past 10 fiscal years. The section called 'Advocacy on Capitol Hill' gives visitors the opportunity to sign up for FASEB e-action alerts that provide updates on public policy issues. Members of the public can sign on to letters to their legislators about important science-related legislation. There are also links to NIH funding data, science and education data, and FASEB's numerous advocacy and information publications.

An additional tab in the navigation bar leads to information about FASEB's MARC program (Maximizing Access to Research Careers). There is a lot to read there: resources for underrepresented minority students and scientists, included mentoring, travel funds, seminars, career assistance and even a mobile app!

This is a highly informative website that is up to date other than the videos. Although the first page is a little busy visually, the rest of the website is clear and easy to read.

\section{http://www.faseb.org/}
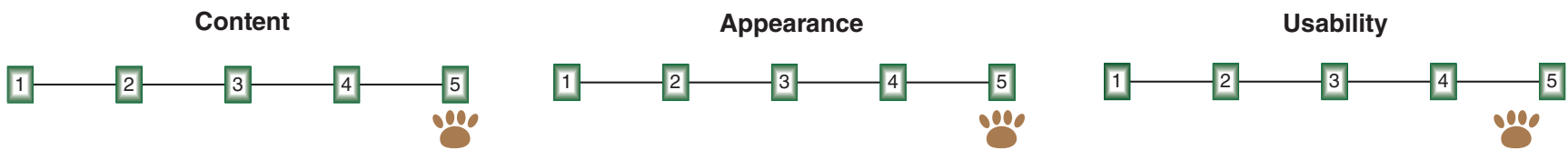